\title{
A Relação entre o Ensino de Ciências da Natureza e a Formação da Concepção de Mundo à luz da Psicologia Histórico-Cultural
}

\author{
The Relation between the Teaching of Natural Science and the Formation \\ of the Conception of the World in light of Cultural-Historical Psychology
}

\author{
Juliane Cristina Zocoler ${ }^{1}$ \\ Marta Sueli de Faria Sforni ${ }^{1}$ \\ 'Universidade Estadual de Maringá (UEM), Maringá, PR, Brasil. \\ Autora correspondente: msfsforni@uem.br
}

Resumo: Este artigo apresenta resultados de uma pesquisa realizada com a finalidade de investigar como o ensino de Ciências de Natureza pode contribuir para o desenvolvimento psíquico e de uma concepção de mundo materialista, histórica e dialética dos estudantes, denominada de concepção de mundo para si. Com base em aportes da Teoria Histórico-Cultural, foi elaborado um experimento didático, desenvolvido em uma turma de $7^{\circ}$ ano de um colégio do estado de São Paulo. O experimento didático revelou alguns princípios didáticos que se mostraram favoráveis à promoção da aprendizagem conceitual dos estudantes na perspectiva do desenvolvimento de uma forma teórica de ver, pensar e explicar os fenômenos do mundo, quais sejam: o uso de situaçõesproblema, as discussões coletivas, a elaboração de um modo geral de ação e a leitura dialogada de textos científicos.

Palavras-chave: Ensino fundamental; Pensamento teórico; Situações-problema; Conceito científico; Psicologia histórico-cultural.

\begin{abstract}
This article presents results of research carried out with the purpose of investigating how the teaching of Natural Sciences can contribute to the psychic development of a conception of the world that is materialistic, historical and dialectical among students, which is denominated a conception of the world for the self. Based on aspects of Cultural Theory, a didactic experiment was created to be used in a $7^{\text {th }}$ year class of a school in the state of São Paulo. The didactic experiment revealed some didactic principles that favored the promotion of students' learning of concepts as ways of developing a theoretical form of seeing, thinking and explaining world phenomena, namely collective discussions, the elaboration of a general way of acting, and the dialogue-based reading of scientific texts.
\end{abstract}

Keywords: Elementary school; Theoretical thinking; Problem situations; Scientific concept; Cultural-historical psychology.

Recebido em: 05/07/2019

Aprovado em: 11/10/2019 


\section{Introdução}

Com a intenção de compreendermos a relação entre a forma de ensino dos conteúdos escolares e o aprendizado dos estudantes, o presente trabalho dedica-se a analisar como o ensino de Ciências de Natureza pode contribuir para o desenvolvimento do psiquismo e de uma concepção de mundo materialista, histórico-dialética nos adolescentes escolares.

Partimos do pressuposto de que a função da educação escolar é o desenvolvimento omnilateral dos estudantes, a saber, o desenvolvimento integral das suas capacidades psíquicas. É por meio desse desenvolvimento que o estudante pode formar uma concepção de mundo que o permita ver, compreender e explicar o mundo de forma ampla, real e profunda, à qual denominamos de concepção de mundo para si.

Para tanto, a escola deve constituir-se como o espaço para a transmissão dos conhecimentos já produzidos pela humanidade. Segundo Vygotski (2001), o ensino é a força propulsora do desenvolvimento do psiquismo, portanto, a escola tem a função de transmitir às novas gerações os conhecimentos sistematizados, cuja aprendizagem é a fonte do desenvolvimento psíquico por colocar em curso processos psíquicos que não iriam se desenvolver de outra de forma.

Contudo, não é todo conteúdo e nem toda forma de ensino que promovem desenvolvimento psíquico. É preciso a participação consciente do estudante nas tarefas de estudo dos conceitos científicos, de modo que esses conteúdos sejam internalizados e tornados instrumentos mediadores entre o seu pensamento e os fenômenos da realidade (SFORNI, 2017).

Amparados nesses pressupostos, perguntamo-nos: como o ensino de Ciências da Natureza pode ser organizado de modo que contribua para o desenvolvimento psíquico e para a formação de uma concepção de mundo para si dos estudantes?

Com a intencionalidade de obter respostas, partimos para um estudo teórico e de campo. Na parte teórica buscamos compreender o atual modo de organização do ensino de Ciências da Natureza e seu impacto no aprendizado e no desenvolvimento dos estudantes.

A pesquisa de campo foi realizada no formato de um experimento didático, com uma turma do $7^{\circ}$ ano do ensino fundamental, em uma escola do estado de São Paulo. Buscamos identificar e analisar ações didáticas que se mostram favoráveis à aprendizagem dos conteúdos escolares e ao consequente desenvolvimento psíquico dos estudantes.

\section{Limites da Formação Escolar e a Passagem do Em Si ao Para Si}

Em 2015, o Programa Internacional de Avaliação dos Estudantes (PISA) teve o foco em Ciências da Natureza. A avaliação contou com a participação de 23.141 estudantes brasileiros de 841 escolas. Apesar de a maior parte dos estudantes relatar, no exame, que se interessam por disciplinas relacionadas a ciências, o resultado da avaliação confirmou a precariedade da formação que vem sendo oferecida em nossas escolas. A média que os nossos estudantes obtiveram deixou o Brasil na $63^{\circ}$ posição entre 70 países avaliados (BRASIL, 2016).

Sabemos que esse baixo rendimento é o produto das relações sociais que os estudantes participam. A preocupação da educação escolar não é com a formação integral do indivíduo, mas sim, com a formação de trabalhadores polivalentes que saibam exercer diferentes funções e assim, se adaptar às mudanças da atual forma de organização do trabalho. 
Desse modo, para os trabalhadores é destinada a formação de habilidades e competências, como a autonomia e a criatividade para atender às demandas de um mercado de trabalho em acelerado processo de mudança e, ao mesmo tempo, são requeridas atitudes e valores de solidariedade, de cooperação, de harmonia e de respeito às diferenças que deixam de serem vistas como produto da desigualdade social e passam a ser tratadas como diversidade e, portanto, consideradas como algo a ser respeitado e não superado. $\mathrm{A}$ problemática daí decorrente é que a luta de classes por uma formação humana dilui-se em um discurso de respeito à diversidade.

Sob a justificativa de um ensino que respeita as diferenças individuais, criam-se níveis qualitativamente distintos de ensino.

\footnotetext{
De fato, o elevado grau de competitividade ampliou a demanda por conhecimentos e informações e, em decorrência, a educação foi eleita estratégica para fazer face à velocidade das mudanças. Se o mundo virou pelo avesso, a educação deve acompanha-lo na reviravolta. A escola tradicional, a educação formal, as antigas referências educacionais, tornam-se obsoletas. É preciso, agora, elaborar uma nova pedagogia, um projeto educativo de outra natureza. $\mathbf{O}$ discurso é claro: não basta apenas educar, é preciso assegurar o desenvolvimento de 'competências' (transferable skills), valor agregado a um processo que, todavia, não é o mesmo para todos. Para alguns, exige níveis sempre mais altos de aprendizagem, posto que certas 'competências' repousam no domínio teórico-metodológico que a experiência empírica, por si só, é incapaz de garantir. Para a maioria, porém, bastam as 'competências' no sentido genérico que o termo adquiriu hoje em dia, e que permitem a sobrevivência nas franjas do núcleo duro de um mercado de trabalho fragmentário, com exigências cada vez mais sofisticadas e níveis de exclusão jamais vistos na história. (MORAES, 2001, p. 8, grifos nossos).
}

Com efeito, o afastamento da educação escolar de um ensino destinado à aprendizagem dos conteúdos mais eruditos em favor do desenvolvimento das forças produtivas, tem como resultado um rebaixamento da qualidade do ensino. Conforme Libâneo (2016), nesse modelo, a escola pública torna-se uma instituição de acolhimento para os pobres, de integração social e moderadora de conflitos. Sua função fica limitada ao cuidado, em detrimento do ensino dos conteúdos significativos para o desenvolvimento do estudante.

Conforme apresentado pela filósofa húngara Agnes Heller (HELLER, 1991), em sua obra Sociología de la vida cotidiana, a vida do indivíduo comporta dois grandes âmbitos: o cotidiano e as formas não-cotidianas da atividade humana.

A autora situa na esfera cotidiana, a qual denomina de objetivações genéricas em si, a linguagem, os usos e costumes e os objetos. Tal nível é considerado em si porque o aprendizado ocorre espontaneamente, isso é, de forma pragmática, em decorrência do convívio social com outros indivíduos. Por exemplo, a criança aprende a falar a língua materna, a utilizar os objetos (escova de dente, talheres, celular entre tantos outros), e a reproduzir os costumes do local onde vive em razão da relação e da comunicação que estabelece com os adultos, sem que tenha necessariamente consciência disso (HELLER, 1991).

Já a apropriação das objetivações genéricas para si demanda do indivíduo uma relação mais consciente com o objeto a ser apropriado. A esse grupo pertencem a ciência, $a$ arte e a filosofia, cuja apropriação requer a superação da forma espontânea, imediata e pragmática, própria do cotidiano, por uma atividade intencional e conscientemente dirigida para esse fim (DUARTE, 2013; HELLER, 1991). 
A passagem do caráter cotidiano do conhecimento para o caráter não cotidiano, quer dizer, do em si ao para si, corresponde a um processo dialético de superação por incorporação. Não existe uma separação rígida entre o em si e o para si (DUARTE, 2013). Conforme Heller (2004), o em si é uma unidade vital formadora e necessária à própria vida do indivíduo. Mas é a apropriação das objetivações genéricas para si que proporciona a superação da cotidianidade e o avanço para a formação de uma individualidade para si.

Portanto, o em si e o para si, são esferas do conhecimento que permitem ao sujeito ter o domínio e o controle da natureza e de si, mas somente as objetivações genéricas para si são "[...] objetivações das relações dos indivíduos com o gênero humano [...]", e, portanto, guardam "[...] o máximo grau de liberdade que o gênero humano alcançou em uma determinada época histórica" (DUARTE, 2013, p. 152).

Com efeito, o ensino e a apropriação dos conteúdos científicos, artísticos e filosóficos torna-se condição para a formação da concepção do mundo dos indivíduos, a saber, "[...] tudo aquilo que caracteriza a conduta global do homem, a relação cultural da criança com o mundo exterior [...]" (VYGOTSKI, 2000, p. 328), dito de outra forma, a concepção de mundo refere-se a um corpo de conhecimentos e posicionamentos valorativos acerca do mundo, da vida, da sociedade, das pessoas e de si próprio, pelos quais o indivíduo guia a sua conduta. (DUARTE, 2016).

No entanto, os conhecimentos não são isentos de políticas e de ideologias. Algumas ideias podem ser internalizadas de forma espontânea, bastante incoerentes e desarticuladas, deixando o indivíduo limitado a uma concepção de mundo em si.

A superação dessa condição requer o desenvolvimento de uma forma superior de pensamento. Para a psicologia histórico-cultural, a adolescência é a etapa privilegiada para o desenvolvimento do ser humano. É o período em que ocorrem as principais mudanças no psiquismo e na vida do indivíduo. A partir da adolescência, o sujeito pode desenvolver uma forma de pensamento superior, denominada por Vygotski (2001) de pensamento por conceitos, e, por ele, dominar seus atos de pensamento e sua conduta.

Para Leontiev (2004), é o período propício para o desenvolvimento de reflexões sobre o mundo. O adolescente passa a ter interesses teóricos, isso é, quer conhecer não apenas a realidade existente, mas também os conhecimentos que existem sobre ela:

Do ponto de vista de consciência, esta passagem à última idade escolar é marcada pelo desenvolvimento de uma atitude crítica face às exigências, às maneiras de agir, às qualidades pessoais dos adultos e pelo aparecimento de interesses novos pela primeira vez verdadeiramente teóricos. Nos alunos maiores, aparece a necessidade de conhecer não apenas a realidade que os rodeia mas igualmente o saber que existe sobre a realidade (LEONTIEV, 2004, p. 309).

Nesse sentido, Davidov (1988) afirma que a escola deve preocupar-se com o planejamento e com a organização de um ensino, em que as tarefas escolares estejam orientadas à formação de um pensamento teórico. Porém, como não é todo conteúdo e nem toda forma de ensino que propiciam essa formação, torna-se necessário a identificação de práticas educacionais que contribuam para a superação das limitações impostas pelo sistema capitalista, com vistas à promoção de uma educação escolar voltada para o ensino dos conhecimentos eruditos, de modo que os estudantes tenham o acesso e a possibilidade 
de desenvolver um pensamento ao nível dos conhecimentos mais evoluídos já produzidos e, assim, ver, compreender e explicar teoricamente os fenômenos do mundo.

Nessa busca, desenvolvemos um experimento didático para analisar modos de organização do ensino que apresentam potencial para promover o desenvolvimento desse tipo de pensamento. Por meio do experimento, o pesquisador não apenas observa as situações de sala de aula, mas exerce um papel ativo, criando situações para investigação dos fenômenos que almeja estudar, de modo que possa identificar as suas origens e a suas causas (AQUINO, 2014; DAVIDOV, 1988).

\section{A Organização do Experimento Didático}

A escolha da aplicação de um experimento didático partiu das defesas de Rubinstein (1973) e Vygotski (2001) de que a criança se desenvolve sob a influência de certo modo de ensino, logo, deve ser estudada enquanto é ensinada. Assim, organizamos uma sequência didática, na qual procuramos identificar e analisar as relações entre as ações de estudo e o movimento do pensamento dos estudantes, de modo a identificar aquelas que oportunizam o desenvolvimento psíquico.

O experimento didático foi desenvolvido com uma turma de 25 estudantes do 70 ano do ensino fundamental de uma escola estadual, situada em um município do oeste do Estado de São Paulo. A unidade escolar está localizada em uma área periférica do município. Conforme o disposto no Projeto Político Pedagógico, a instituição atende a estudantes do $6^{\circ}$ ao $9^{\circ}$ ano do ensino fundamental e do ensino médio, contando com aproximadamente 550 estudantes, oriundos de vários bairros do município e também da zona rural. A maior parcela dos estudantes pertence a uma comunidade de baixo nível sócio/econômico/cultural e o nível de escolarização da maioria dos pais é baixo.

O experimento totalizou 24 horas-aula e foi desenvolvido pela própria pesquisadora que já atuava como professora de Ciências da Natureza dessa turma desde o início do ano letivo. As aulas foram videogravadas e as produções dos alunos, copiadas, para que esses materiais pudessem se tornar fontes de pesquisa.

A unidade de análise dessa pesquisa foi o conceito objetivado na palavra, pois, conforme Vygotski (2001), a palavra é a expressão do pensamento e da linguagem. Dessa forma, há uma profunda relação entre o significado da palavra - o conceito -, e a estrutura da consciência. Luria (1979) nos explica que podemos utilizar sempre uma mesma palavra/ conceito para denominar certo objeto ou fenômeno, como amendoeira e pinheiro, mas no decorrer o desenvolvimento, a consciência do ser humano pode criar relações e formar conceitos mais genéricos, como árvore e vegetal, que abarcam vários seres/objetos/ fenômenos, e por isso, enriquecem e ampliam as concepções dos indivíduos, uma vez que desprendem o pensamento da interação sensorial imediata com a realidade.

Assim, entendemos que, durante a realização do experimento - no processo de ensino e de aprendizagem dos conceitos -, os significados que os estudantes atribuem às palavras/conceitos podem revelar se o estudante está estabelecendo conexões mais amplas, inserindo-as em um determinado sistema conceitual. Logo, a nossa investigação teve como objetivo identificar ações didáticas que possam favorecer essa mudança conceitual.

Para a elaboração da sequência didática partimos de três ações apontadas por Sforni (2017) como fundamentais para um ensino que priorize a formação de um pensamento 
teórico: a análise do sujeito da aprendizagem, a análise da gênese do conceito e a análise das tarefas de ensino que mobilizam as funções psíquicas superiores.

\section{A Análise do Sujeito da Aprendizagem}

A turma era composta por adolescentes na faixa etária de 12 e 13 anos. Como afirmado anteriormente, esses estudantes estão em um período da vida em que surgem importantes mudanças internas que são muito mais profundas daquelas geradas pela maturação sexual e exteriorizadas no corpo. Há um importante desenvolvimento funcional do cérebro, especialmente do córtex cerebral, ligado às novas e mais complexas condições da vida (ELKONIN, 1960).

Para a psicologia histórico-cultural, a adolescência é o momento de grandes possibilidades formativas: o desenvolvimento de um pensamento superior denominado de pensamento teórico por Davidov (1988), assim como, de um pensamento por conceitos e a formação das sínteses superiores - a personalidade e a concepção de mundo, segundo Vygotski (2006).

Conforme Elkonin (1960), a adolescência é uma fase marcada pelo "código de companheirismo" em que o sujeito reproduz, com os seus coetâneos, a forma de relacionamento dos adultos, especialmente, dos adultos que são tomados pelo adolescente como "modelos" ideais de formação. Nessa reprodução estão incluídas as regras morais e éticas que permitirão a ele formar os pontos de vista gerais sobre o mundo, a sociedade, as pessoas, como também, sobre si, sobre o seu próprio futuro e sobre o sentido de sua vida.

O homem, dizia Hegel, é uma criança cuja tarefa não consiste em permanecer no abstrato e incompleto 'em-si', mas sim em ser também 'para-si', isto é, converter-se em um ser livre e racional. Pois bem, essa transformação da criança, de ser humano em-si, em adolescente - o ser humano para-si - configura o conteúdo principal de toda a crise da idade de transição. Nessa época amadurece a personalidade e sua concepção de mundo, é o período das sínteses superiores produzidas pela crise do devir e o amadurecimento daquelas formações superiores que são o fundamento de toda a existência consciente do ser humano. (VYGOTSKI, 2006, p. 200).

Assim, embasados na periodização do desenvolvimento psíquico apresentada por Elkonin (1960), que nos diz quem é o sujeito da aprendizagem, organizamos o experimento didático com tarefas de estudo em que os estudantes tivessem que trabalhar em grupo para resolver situações-problema e formular sínteses. Entendemos que as discussões em grupo, entre seus coetâneos, ocasionadas pela tentativa de solução das situações-problema, criam uma situação interna que favorece a formação do interesse e do motivo pelo estudo, assim como, a tomada de consciência das suas próprias ações mentais, o que pode resultar em uma reorganização do seu pensamento.

Cumpre destacar que quando falamos da formação do interesse pelo estudo, não estamos nos referindo aos desejos e aspirações imediatas e cotidianas dos estudantes, mas àquele vinculado à criação, na própria atividade de ensino, da necessidade e dos motivos para o aprendizado do conteúdo escolar. Entendemos que esse processo pode ser incitado por meio da compreensão da necessidade e da atividade humana histórica que está encarnada nos conhecimentos das ciências. 


\section{A Análise da Gênese do Conceito}

A escolha dos conceitos a serem trabalhados no experimento didático atendeu ao conteúdo que estava definido na proposta curricular da instituição: os microrganismos e a conservação dos alimentos. Além disso, em nossas experiências de sala de aula, identificamos que a atual organização do ensino desse conteúdo, embora aborde conceitos científicos, não tem possibilitado que os estudantes superem concepções de senso comum envolvendo a ação dos microrganismos, mantendo-os limitados em concepções muitos distantes e distorcidas da realidade, fato confirmado por várias pesquisas como as de: Gonçalvez (2012), Oliveira, Azevedo e Sodré Neto (2016), Sforni e Galuch (2006), Silva, Costa e Santos (2016), Silveira, Oliveros e Araújo (2011). Todas elas revelam que os estudantes apresentam conhecimentos muito vagos em relação à existência e as atuações dos microrganismos. Esses seres são associados a animais, especialmente a insetos, e com uma conotação quase sempre negativa, vinculada às doenças e à sujeira.

Com a intenção de superar essas concepções, partimos para a análise do conceito de microrganismos e da atuação desses seres sobre os alimentos. Começamos com a reflexão: o que é nuclear nesse conceito? É um conhecimento produzido pela humanidade com o objetivo de conhecer e controlar quais fenômenos da realidade? (SFORNI, 2017). Seguimos então, para o estudo da gênese e do desenvolvimento desse conceito ao longo da atividade histórica humana.

O estudo dos microrganismos foi fortemente influenciado pela necessidade de conhecimento das doenças que afetavam as pessoas. Porém, a conservação dos alimentos é também uma atividade humana que vem sendo praticada ao longo do tempo a fim de garantir a sobrevivência das comunidades. O ser humano primitivo já sentia a necessidade de armazenar os alimentos para dias em que ele poderia não ter sucesso com a caça, para determinadas épocas do ano em que o alimento não era tão abundante, para dias frios, chuvosos, ou seja, para períodos em que se tornava mais difícil a obtenção de comida.

Os procedimentos para a conservação dos alimentos surgiram pela observação direta dos fenômenos. As tentativas bem-sucedidas, descobertas ao acaso, eram repassadas de uma geração a outra. A secagem e o uso do sal (salga) foram provavelmente as primeiras técnicas. Mais tarde, com a descoberta do fogo, o ser humano pode criar o processo de defumação.

O grande salto nos conhecimentos sobre os microrganismos foi a partir da idade de ouro da microbiologia, entre 1857 e 1914, período em que os avanços na microscopia permitiram a descoberta das atividades químicas dos microrganismos e o estudo de técnicas de cultivo desses seres (PELCZAR; REID; CHAN, 2005).

Assim, entendemos que as abstrações criadas nesse campo, ou seja, a produção de conhecimentos científicos sobre os microrganismos foi uma necessidade humana de controlar e fazer uso da ação desses seres, portanto, compreender as condições de reprodução dos microrganismos foi fundamental para o ensino das técnicas de conservação dos alimentos, permitindo a compreensão e a intervenção em diversos fenômenos da realidade. Essa análise nos fez considerar que as condições de reprodução dos microrganismos era conceito nuclear a ser apropriado pelos estudantes. 


\section{A Análise das Tarefas de Ensino que Mobilizam as Funções Psíquicas Superiores}

A aprendizagem de um conceito requer a participação ativa do estudante no processo de apropriação, ou seja, para que ele possa apropriar-se de um conceito, precisa reproduzir internamente a atividade humana que se encontra objetivada nesse conceito (LEONTIEV, 2004), realizando o movimento de redução do concreto ao abstrato e de ascensão do abstrato ao concreto (DAVIDOV, 1988). Dessa forma, procuramos elaborar ações didáticas de modo a mobilizar suas funções psíquicas superiores. Entendemos que essa mobilização pode ser alcançada quando inserimos o estudante em situações-problema, em discussões com o grupo, com a aplicação de um modo geral de ação, com a leitura dialogada de textos científicos e com a resolução de um novo problema mediada pelo sistema conceitual que foi objeto de ensino.

Embasados na a nálise dos elementos já expostos - o sujeito da aprendizagem, a gênese do conceito e as tarefas mobilizadoras das funções psíquicas superiores - organizamos as seguintes ações de ensino:

$1^{\circ}$ momento: 12 horas-aula: divisão dos estudantes em 5 grupos, apresentação das situações-problema, diálogos nos grupos e elaboração de um modo geral de ação.

$2^{\circ}$ momento: 5 horas-aula: o uso da linguagem científica.

$3^{\circ}$ momento: 5 horas-aula: elaboração de uma síntese conceitual.

$4^{\circ}$ momento: 2 horas-aula: avaliação do processo de ensino.

\section{Os Episódios de Ensino}

Diante da grande quantidade de material coletado durante o experimento didático, a análise dos dados, que visava captar o movimento do pensamento dos estudantes, não se pautou na descrição linear e detalhada de todas as ações, mas na apresentação de episódios de ensino.

O termo episódio refere-se a:

[...] frases escritas ou faladas, gestos e ações que constituem cenas que podem revelar interdependência entre os elementos de uma ação formadora. Assim, os episódios não são definidos a partir de um conjunto de ações lineares. Pode ser que uma afirmação de um participante de uma atividade não tenha impacto imediato sobre os outros sujeitos da coletividade. Esse impacto poderá estar revelado em um outro momento em que o sujeito foi solicitado a utilizar-se de algum conhecimento para participar de uma ação no coletivo (MOURA, 2004, p. 276).

Portanto, episódio de ensino é "[...] aquele momento em que fica evidente a situação que queremos investigar [...]" (CARVALHO et al., 1993, p. 249). Ou seja, são momentos que evidenciam as relações essenciais e as múltiplas determinações dos fenômenos, de forma a possibilitar a compreensão para além de sua aparência externa e imediata.

Dessa forma, apresentaremos a seguir alguns episódios de ensino que julgamos ser ilustrativos da relação entre as ações didáticas desenvolvidas no experimento e o impacto delas na aprendizagem dos estudantes. 
Com o objetivo de incitar reflexões a respeito de fenômenos sobre os quais, muitas vezes, os porquês não são compreendidos pelos indivíduos, realizamos o experimento didático com a apresentação de situações-problema para cada um dos conceitos relacionados à reprodução dos microrganismos, quais sejam: pressão osmótica, nutrientes, temperatura e potencial de hidrogênio $(\mathrm{pH})$. A primeira situação foi a seguinte:

- Hoje conservamos alimentos em geladeiras e freezers, mas como as pessoas faziam para armazenar alimentos quando não existiam esses eletrodomésticos? Por exemplo, um agricultor matava uma vaca para alimentar a sua família, mas eles não comiam a carne toda de uma vez. Como será que eles faziam para que o restante da carne não estragasse e pudessem consumi-la aos poucos?

Logo começaram a surgir nos grupos falas como:

\section{Grupo 3}

Ta: Tinha alguma coisa para a carne não estragar. Acho que eles colocavam bastante tempero e colocavam dentro de um pote.

Professora: Tempero?

Ra: Colocava sal para não estragar [estudante se mostra pensativa]. Mas eu acho que mesmo colocando muito sal ainda apodrece.

\section{Grupo 5}

Ka: Eu acho que eles colocavam a carne no Sol, prof. Aí ficava bem branco de sal. Aí deixava lá dependurada. [...] aí depois de um tempo ia lá, lavava e comia... Meu tio fazia isso.

[O grupo seguiu com o diálogo e depois de um tempo formularam a seguinte síntese que foi compartilhada com a sala]

Ka: Antigamente, eles pegavam a carne e como não tinha geladeira essas coisas, eles jogavam bastante sal para conservar e colocavam no varal e deixava dependurada, aí quando eles queriam a parte deles ia lá, tirava, lavava que as moscas vão lá pousa e tal [risos dos estudantes] e lava e depois come.

As falas dos estudantes, especialmente a de $\mathrm{Ka}$, ao relatar que viu o seu tio realizar os procedimentos de adição de sal e de exposição da carne ao Sol, deixaram evidente que eles procuravam resolver a situação utilizando conceitos espontâneos. Porém, embora a situação-problema apresente uma situação prática, ela foi elaborada como um problema de aprendizagem, de modo a exigir dos estudantes soluções mediadas pelos conceitos científicos em estudo.

Para resolver tarefas de caráter utilitário, o conhecimento empírico, embasado na percepção imediata e direta da aparência do objeto, é suficiente (DAVIDOV, 1988). Mas, esse tipo de conhecimento não revela a essência e as condições de existência do fenômeno, algo indispensável para a sua compreensão, e que só pode ser alcançado com o conhecimento teórico.

A fim de fazer a discussão avançar mostramos figuras de carnes salgadas e pedimos que os estudantes respondessem o questionamento: Por que será que a carne não estraga tão rápido quando ela é salgada? O que o sal impede?

Prosseguimos acompanhando os diálogos dos grupos: 


\section{Grupo 3}

Professora: O que é isso?

Gui: Carne de varal com sal. Eu falei professora para esse grupo, eu falei! Mas ninguém falou nada.

Professora: Vocês já viram isso?

Grupo: Sim, o peixe, o bacalhau.

Professora: Agora vem a pergunta: Por que o sal ajuda a conservar a carne?

Ra: Para afastar as moscas?

Professora: Para afastar as moscas e o que mais?

Gui: Ah, para evitar o bolor.

Professora: E o que é o bolor?

Ra: Microrganismos.

Professora: Então o sal afastava as moscas e ...

Gui: Os fungos.

Professora: Fungos são?

Ra: Microrganismos.

Professora: Então, agora conversem mais um pouco pensando em como o sal ajuda a conservar a carne por mais tempo.

Os diálogos estabelecidos nesse grupo, particularmente, com os estudantes Ra e Gui evidenciam um movimento do pensamento. Na tentativa de solucionar uma situação que não fazia parte do seu cotidiano, a conservação da carne sem o uso das atuais tecnologias, os estudantes precisaram mobilizar as suas funções psíquicas superiores. Eles tiveram que dirigir e concentrar a atenção para a problemática, estabelecer relações entre conceitos já aprendidos, buscar na memória o conhecimento sobre os microrganismos como os seres que fazem a decomposição da matéria morta, imaginar possíveis hipóteses e desenvolver raciocínios para encontrar a resposta.

Após acompanhar as discussões de todos os grupos, partimos para a explicação do conceito de pressão osmótica. Elaboramos, em conjunto com os estudantes, um modelo gráfico, denominado de modo geral de ação (Figura 1), por sintetizar o sistema conceitual que pretendíamos ensinar. Segundo Davidov (1988) o que é característico em um modelo é a presença de um fenômeno nuclear do qual partem outros fenômenos associados e relacionados entre si. Assim, o modelo ficou da seguinte forma:

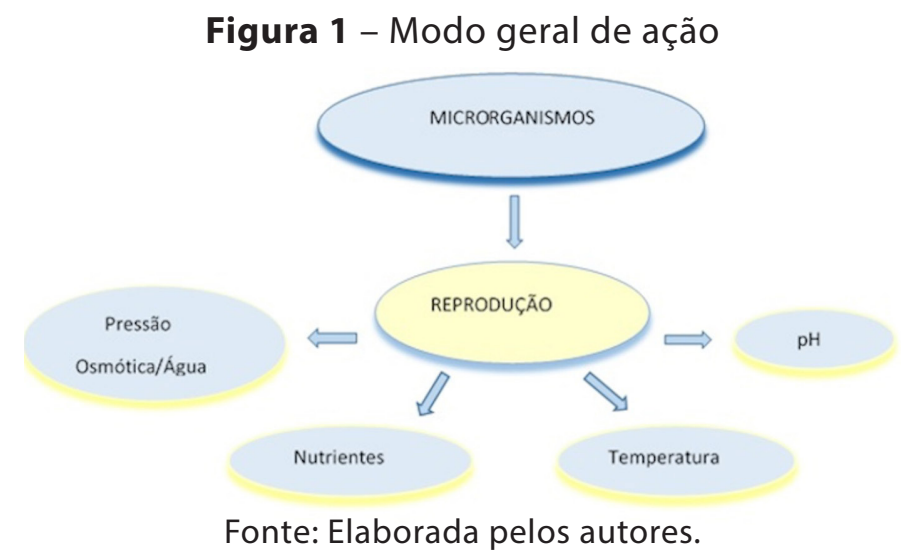

Cumpre dizer que o modelo começou a ser construído com o conceito de reprodução, já que ele guarda as relações essenciais entre diferentes fenômenos. Os conceitos que expressam os outros fenômenos foram sendo incluídos no modelo à medida que as atividades de estudo avançavam. 
$\mathrm{Na}$ análise de alguns episódios identificamos que algumas respostas evidenciavam uma generalização acerca da presença dos microrganismos nos alimentos, processo que julgamos ter sido facilitado com a utilização do modo geral de ação.

Nas sínteses definitivas que os grupos deveriam formular e também em respostas dadas às situações-problema elaboradas com um contexto distinto para a avaliação ao fim do experimento didático, observamos algumas respostas, tais como:

Parte da síntese do grupo 4: [...] temperaturas muito baixas os microrganismos não conseguem se reproduzir ficando estagnado. Na qual os números não aumentam controlando assim a atividade além de haver outros métodos de controlar a reprodução, como a adição de $\mathrm{pH}$ ácido que impedi que os microrganismos continua vivendo neste local, além de retirar a agua deste local que é a principal fonte principal da reprodução dos microrganismos [...].

Pergunta realizada na avaliação:

- A Amazônia é uma enorme floresta equatorial localizada na América do Sul com clima quente e úmido. Apesar da exuberância apresentada pela floresta, o solo no qual está fixada é pobre. No entanto, sob esse solo pobre encontra-se uma restrita camada de matéria-orgânica, conhecida como húmus. É uma camada muito fértil e oriunda da própria floresta, na qual seres vivos, como as bactérias e os fungos, reciclam os nutrientes dispostos no ambiente. Pensando nas condições ambientais da Floresta Amazônica, quais seriam os fatores que possibilitam a vida e a reprodução dos microrganismos nesse local? Por quê?

Dê: Umidade, nutrientes e temperatura. Eles gostam do ambiente úmido, pois possui um pouco de água. Eles precisam de nutrientes para a reprodução, crescer em número e não em tamanho. E a temperatura tem que ser ambiente, pois é uma das adequadas para a reprodução.

Lê: A água de lagos e rios, o húmus, animais mortos, frutos de arvores caídos no chão, também a umidade do ar e etc. Porque são alimentos que têm nutrientes e água no qual eles precisão para sobreviver.

Essas respostas indicam que os estudantes estabeleceram relações entre as várias técnicas de conservação dos alimentos e a tentativa de controle da reprodução dos microrganismos, provavelmente, favorecidas pela internalização do modo geral de ação.

Além da resolução de situações-problema em grupos e da elaboração de um modo geral de ação, trabalhamos com a leitura dialogada de textos científicos que foram elaborados especificamente para cada conteúdo. Para a escrita dos textos, apoiamo-nos em livros e artigos acadêmicos de Microbiologia, mas os adaptamos aos nossos objetivos, utilizando uma linguagem razoavelmente próxima do nível de desenvolvimento real dos estudantes.

Partindo da defesa de Leontiev (2004) de que a apropriação de um conceito requer a reprodução da atividade humana que Ihe deu origem, os textos trabalhados em sala de aula devem permitir aos estudantes conhecer a história da elaboração daqueles conhecimentos, ou seja, reconhecê-los como uma produção destinada a solucionar um problema real da humanidade em um dado período histórico. 
Explicamos aos estudantes que a leitura dos textos seria de forma dialogada, quer dizer, que eles não iriam fazer a leitura sozinhos. Dessa forma, a professora/pesquisadora realizava a leitura e, a cada parágrafo, questionava os estudantes sobre o significado de certas palavras e dos conceitos alvo do trabalho, assim como, do conteúdo geral que o texto apresentava.

Conforme Vygotski (2001) a força dos conceitos científicos está em sua alta capacidade de síntese, de sistematização e de generalização, o que permite ao pensamento libertar-se das situações particulares e expressar a universalidade. Ou seja, é diante da linguagem científica que os estudantes têm a possibilidade de confrontar seus conhecimentos cotidianos com os conhecimentos produzidos historicamente pelo conjunto dos homens. Assim, dialogar com textos científicos

[...] exige que o leitor saia de uma visão já consolidada sobre alguns fenômenos e insira o olhar do outro. Nessa interação, ele pode modificar, complementar, incorporar, consolidar ou abandonar o pensamento pré-existente, ampliando seu repertório cultural (BELIERI; SFORNI, 2017, p. 700, grifo dos autores).

Portanto, a interação com a linguagem científica permite que os estudantes se distanciem momentaneamente das situações práticas, para pensar no conceito e depois voltar a elas com um novo olhar.

Podemos evidenciar esse movimento do pensamento dos estudantes nos diálogos que surgiram durante a leitura do texto que apresentava os três grupos principais de microrganismos, de acordo com a faixa de temperatura ideal para a sua reprodução, a saber: psicrófilos, mesófilos e termófilos.

Ra: Professora, eu vi uma reportagem que tem um deserto, não sei qual nome, que foi encontrada a maior temperatura. A Nasa foi lá, pegou o termômetro e mediu e era $70^{\circ} \mathrm{C}$ e, então, eles conseguiriam se reproduzir e sobreviver lá normal?

Professora: Sim! Se chegasse a $90^{\circ}$ seria melhor ainda.

Dê: Se estiver muito frio eles sobrevivem?

Sala: Não!

Professora: Cada um tem a sua faixa de temperatura ideal para reprodução $e$ sobrevivência.

Guil: É assim, se $35^{\circ}$ é ótimo, mas se mudar para $37^{\circ}$ já muda a reprodução.

Professora: Isso, uma mudança, por exemplo, nos mesófilos, em que a melhor é $35^{\circ}$ ou

$36^{\circ}$, se for a partir de $40^{\circ}$ já tem o decréscimo da curva, eles já não se reproduzem tão bem.

Guil: É que cada um tem a sua característica.

Professora: Sim! É característica deles e cada um tem um padrão de reprodução.

Dê: Prô, ali naquele padrãozinho ali [apontando para uma curva de crescimento que havíamos feito na lousa] se chegar, se for um pouco maior só que para cá [apontando o lado direito] ele não consegue se reproduzir mais?

Professora: O texto está dizendo que a melhor reprodução dos microrganismos acontece aqui no pico na curva [fomos à lousa para mostrar o pico da curva]. Então, no caso dos mesófilos, a temperatura ideal é $36^{\circ} \mathrm{C}$. [escrevemos $36^{\circ}$ no pico da curva], se vai para $40^{\circ}$ a taxa de reprodução começa a diminuir, mas só vai parar de ocorrer nas extremidades da curva.

Ra: Ah! Eu tenho anotado aqui. As frutas está no 2 e 3 aqui o que é bastante ácido e carne e o leite está no 5 e 6, perto do 7.

Professora: Isso mesmo! Não aparece aqui, mas eu falei na aula passada, anotem aí, a carne e o leite estão entre o 5 e $6 \mathrm{de} \mathrm{pH}$, perto da neutralidade, por isso são alimentos que se deterioram rapidamente em temperatura ambiente. 
Nesse episódio, as falas de Guil, de Ra e as perguntas feitas por Dê evidenciam que os estudantes estavam em processo análise e síntese diante da linguagem científica. Vale lembrar que esse movimento do pensamento é condição para a apropriação dos conceitos e, consequente, do desenvolvimento de uma forma teórica de ver e pensar o mundo.

Os estudantes procuravam estabelecer relações entre os conceitos e as situações particulares. Ra relacionou o conceito de microrganismos termófilos a uma reportagem que leu e logo depois, foi além. Ela conseguiu estabelecer relações entre os conceitos de temperatura e de $\mathrm{pH}$ com a conservação das frutas, das carnes e do leite. Esses são indícios do movimento do pensamento que vai do abstrato ao concreto, isto é, da capacidade de generalizar, de olhar para distintos fenômenos e encontrar neles uma mesma essência.

\section{Resultados}

Com base nos estudos teóricos e no experimento didático desenvolvido, chegamos à identificação de algumas ações de ensino que se mostraram favoráveis ao desenvolvimento psíquico dos estudantes, uma vez que foram capazes de mobilizar e colocar em cursos os processos mentais de reflexão, análise e síntese dos estudantes, de modo que os conhecimentos fossem internalizados e assumidos como instrumentos de mediação entre o seu pensamento e fenômenos do mundo objetivo.

As ações de ensino que destacamos foram as seguintes:

a) o uso de situações-problema;

b) as discussões coletivas;

c) a elaboração de um modo geral de ação;

d) a leitura dialogada de textos científicos.

A utilização de situações-problema permite ao professor a condução do pensamento do estudante ao conceito nuclear a ser apropriado, assim como, a reprodução da necessidade/ atividade humana que deu origem à produção daquele conhecimento. Ao tentar responder a uma situação concreta, cria-se uma situação de vivência, os estudantes percebem a limitação do seu pensamento e sentem a necessidade do estudo, ou seja, de ir buscar no conteúdo científico as respostas para a resolução do problema. É, portanto, nesse movimento que surgem o interesse e o motivo para o estudo.

As discussões nos grupos e entre os grupos permitem que o professor acompanhe o nível do pensamento dos estudantes, de modo a poder fazer intervenções para direcionar a atenção deles para os traços essenciais dos conceitos. A interação entre pares favorece um movimento a princípio interpsíquico, mas que pode conduzir a uma reorganização do pensamento, um movimento intrapsíquico, que resulta na aprendizagem de novos conhecimentos e de uma forma de pensar teoricamente.

Conforme Davidov (1988), o desenvolvimento do pensamento teórico requer a apropriação de um princípio geral explicativo, quer dizer, um sistema de conceitos com um núcleo, um conceito central, pelo qual, diferentes fenômenos da realidade podem ser analisados e explicados. Assim, a utilização de um modelo que sintetize as relações conceituais, facilita a compreensão da estrutura geral do sistema de conceitos e dirige a atenção dos estudantes para a memorização, de forma compreensível, do que é nuclear em determinado conteúdo. 
Por fim, destacamos a leitura dialogada de textos científicos. O domínio da linguagem escrita é condição para que os estudantes possam aprender os conteúdos de todas as áreas do conhecimento. Porém, é preciso que os estudantes dirijam a sua atenção para as palavras que representam os conceitos a serem estudados. Para isso, entendemos que a intervenção do professor durante a leitura de um texto, questionando os estudantes quanto aos significados das palavras e dos conceitos, e dirigindo a atenção deles para lógica de um sistema conceitual, é fundamental para a apropriação dos conhecimentos científicos.

Com efeito, essas ações docentes que destacamos buscam estabelecer a relação entre os estudos teóricos e a prática docente. Porém, não se trata da produção de um receituário e tampouco de uma sequência de passos, mas da compreensão de alguns princípios didáticos a serem levados em consideração na organização de um ensino que preze o desenvolvimento psíquico dos estudantes.

\section{Considerações Finais}

Realizamos esta investigação mobilizados pela necessidade de compreender os motivos do baixo desempenho que os nossos estudantes vêm apresentando nos exames oficiais como também nas práticas que observamos em salas de aula. Entendemos que as últimas décadas foram marcadas por uma política educacional marcadamente neoliberal, em que a formação escolar volta-se para o desenvolvimento de competências e habilidades que atendam às necessidades da atual forma de organização do trabalho. Por essa razão, defende-se a necessidade de formação de indivíduos autônomos, criativos e competitivos que tenham condições de atuar no mercado de trabalho, ao mesmo tempo, exige-se a formação de valores e atitudes necessários à manutenção da coesão social, como a solidariedade, tolerância, convivência e respeito às diferenças, frente às contradições que emergem no contexto da sociedade capitalista e globalizada.

Tais competências e habilidades ganham centralidade na educação escolar, uma vez que podem ser utilizadas como meios de uma formação que permita a reprodução da ordem capitalista. Por terem unicamente essa função, elas são tratadas de forma desvinculada dos conhecimentos científicos, artísticos e filosóficos.

Entendemos, porém, que a educação escolar deve possibilitar que os estudantes, se apropriem cada vez mais dos conhecimentos eruditos, de modo que possam desenvolver um pensamento em nível teórico e uma concepção de mundo que Ihes permita ver, compreender e intervir na realidade objetiva.

Contudo, não basta somente a presença do conteúdo científico nas práticas escolares. É preciso que o ensino dos conceitos científicos ocorra por meio de relações diferenciadas, organizadas e dirigidas para que os conhecimentos produzidos e acumulados pela humanidade possam ser internalizados e tornados instrumentos do pensamento dos estudantes.

Na busca por uma organização do ensino de Ciências da Natureza que possa garantir a apropriação desses conhecimentos, identificamos alguns princípios e ações didáticas, já destacadas nos resultados do experimento, que se mostraram favoráveis para que os estudantes realizassem processos de reflexão, análise e síntese durante as tarefas escolares, processos mentais necessários, conforme Davidov (1988), à formação de formas mais teóricas 
de ver e compreender os fenômenos da realidade. Esses princípios e ações didáticas podem instrumentalizar professores no planejamento e desenvolvimento da atividade de ensino.

\section{Referências}

AQUINO, O. F. O experimento didático-formativo: contribuições para a pesquisa em didática desenvolvimental. In: FARIAS, I. M. S.; LIMA, M. S. L.; CAVALCANTE, M. M. D.; SALES, J. A. M. (org.). Didática e prática de ensino na relação com a formação de professores. Fortaleza: EDUECE, 2014. p. 4645-4657.

BRASIL. Ministério da Educação. Apesar de gostar de ciências, estudante vai mal no Pisa. Brasília: Ministério da Educação, 2016. Disponível em: http://portal.mec.gov.br/component/tags/tag/33571. Acesso em: 12 fev. 2018.

BELIERI, C. M,; SFORNI, M. S. F. Ações docentes no ensino de filosofia no ensino médio. Quaestio, Sorocaba, v. 19, n. 3, p. 689-710, dez. 2017. DOI: http://doi.org/d6wz.

CARVALHO, A. M. P.; GARRIDO, E.; LABURÚ, C. E.; MOURA, M. O.; SANTOS, M. S.; SILVA, D.; ABIB, M. L. V. S.; CASTRO, R. S.; ITACARAMBI, R. R.; GONÇALVES, M. E. R. A história da ciência, a psicogênese e a resolução de problemas na construção do conhecimento em sala de aula. Revista da Faculdade de Educação, São Paulo, v. 19, n. 2, p. 245-256, 1993. Disponível em: https://www.revistas.usp.br/rfe/ article/view/33529/36267. Acesso em: 5 jul. 2018.

DAVIDOV, V. La enseñanza escolar y el desarrollo psíquico: investigación psicológica teórica y experimental. Moscu: Progreso, 1988.

DUARTE, N. D. Os conteúdos escolares e a ressureição dos mortos: contribuições à teoria históricocrítica do currículo. Campinas: Autores Associados, 2016.

DUARTE, N. D. A individualidade para si: contribuição a uma teoria histórico-social da formação do indivíduo. 3. ed. rev. Campinas: Autores Associados, 2013.

ELKONIN, D. B. Desarrollo psíquico de los niños. In: SMIRNOV, A. A.; VILLALANDA, F. Psicología. México: Grijalbo, 1960. p. 493-559.

GONÇALVEZ, P. M. M. Os microrganismos no $10^{\circ}$ e $2 .{ }^{\circ}$ ciclos do ensino básico: abordagem curricular, concepções alternativas e propostas de atividades experimentais. 2012. $461 \mathrm{f}$. Tese (Doutorado em Estudos da Criança) - Universidade do Minho, Braga, 2012.

HELLER, A. Sociología de la vida cotidiana. Barcelona: Península, 1991.

HELLER, A. Estrutura da vida cotidiana. In: HELLER, A. O cotidiano e a história. 7. ed. Rio de Janeiro: Paz e Terra, 2004. p. 41.

LEONTIEV, A. O desenvolvimento do psiquismo. São Paulo: Centauro, 2004.

LIBÂNEO, J. C. Políticas educacionais no Brasil: desfiguramento da escola e do conhecimento escolar. Cadernos de Pesquisa, São Paulo, v. 46, n. 159, p. 38-62, 2016. Disponível em: http:// publicacoes.fcc.org.br/ojs/index.php/cp/article/view/3572. Acesso em: 2 set. 2017.

LURIA, A. R. Curso de psicologia geral v. 1: introdução evolucionista à psicologia. Rio de Janeiro: Civilização Brasileira, 1979.

MOURA, M. O. Pesquisa colaborativa: um foco na ação formadora. In: BARBOSA, R. L. L. (org). Trajetórias e perspectivas da formação de educadores. São Paulo: Editora Unesp, 2004. p. 257-284.

MORAES, M. C. M. Recuo da teoria: dilemas da pesquisa em educação. Revista Portuguesa de Educação, Braga, v. 14, n. 1, p. 7-25, 2001. Disponível em: http://www.redalyc.org/articulo. oa?id=37414102. Acesso em: 1 jul. 2018. 
OLIVEIRA, N. F.; AZEVEDO, T. M.; SODRÉ NETO, L. Concepções alternativas sobre microrganismos: alerta para a necessidade de melhoria no processo ensino-aprendizagem de biologia. Revista Brasileira de Ensino Ciências e Tecnologia, Ponta Grossa, v. 9, n. 1, p. 260-276, 2016. Disponível em: https://periodicos.utfpr.edu.br/rbect/article/view/2031. Acesso em: 1 de jul. 2018.

PELCZAR, M.; REID, R.; CHAN, E. C. S. Microbiologia. São Paulo: Pearson: Makron Books, 2005.

RUBINSTEIN, S. L. Princípios de psicologia geral: vol. VI. Lisboa: Estampa, 1973.

SFORNI, M. S. F. O método como base para reflexão sobre um modo geral de organização do ensino. In: MENDONÇA, S. G. L.; PENITENTE, L. A. A.; MILLER, S. (org.). A questão do método e a teoria histórico-cultural: bases teóricas e implicações pedagógicas. Marília: Oficina Universitária; São Paulo: Cultura Acadêmica, 2017. v. 1, p. 81-96.

SFORNI, M. S. F.; GALUCH, M. T. B. Aprendizagem conceitual nas séries iniciais do ensino fundamental. Educar, Curitiba, n. 28, p. 217-229, 2006. Disponível em: http://www.scielo.br/pdf/er/ n28/a14n28.pdf. Acesso em: 1 Jul 2018.

SILVA, A. S.; COSTA, D. W. S.; SANTOS, J. K. R. Micro-organismos: concepções e aprendizagens de estudantes do ensino fundamental maior. Revista de Ensino de Biologia, Niterói, v. 9, p. 4138-4149, 2016. Disponível em: https://sbenbio.org.br/wp-content/uploads/edicoes/revista_sbenbio_n9.pdf. Acesso em: 1 de jul. 2018.

SILVEIRA, M. L.; OLIVEROS, P. B.; ARAÚJO, M. F. F. Concepções espontâneas sobre bactérias de alunos do $6^{\circ}$ ao $9^{\circ}$ ano. In: ENCONTRO NACIONAL DE PESQUISA EM EDUCAÇÃO EM CIÊNCIAS, 8., 2011, Campinas. Anais [...]. Rio de Janeiro: ABRAPEC, 2011. Disponível em: http://www.nutes.ufrj.br/ abrapec/viiienpec/resumos/R0347-1.pdf. Acesso em: 1 de jul. 2018.

VYGOTSKI, L. S. Obras escogidas: tomo II. Madrid: Visor, 2001.

VYGOTSKI, L. S. Obras escogidas: tomo III. Madrid: Visor, 2000.

VYGOTSKI, L. S. Obras escogidas: tomo IV. Madrid: Visor, 2006. 